\title{
Purification and Biological Characterization of Host-Specific SV-Toxins from Stemphylium vesicarium Causing Brown Spot of European Pear
}

\author{
P. Singh, R. Bugiani, P. Cavanni, H. Nakajima, M. Kodama, H. Otani, and K. Kohmoto
}

\begin{abstract}
First and sixth authors: United Graduate School of Agricultural Sciences, Tottori University, Tottori 680-8553, Japan; second and third authors: Servizio Fitosanitario-Regione Emilia-Romagna, Via Corticella 133, Bologna 40129, Italy; fourth author: Laboratory of Applied Microbiology, Faculty of Agriculture, Tottori University, Tottori 680-8553, Japan; fifth and seventh authors: Laboratory of Plant Pathology, Faculty of Agriculture, Tottori University, Tottori 680-8553, Japan.
\end{abstract}

Accepted for publication 8 July 1999.

\begin{abstract}
Singh, P., Bugiani, R., Cavanni, P., Nakajima, H., Kodama, M., Otani, H., and Kohmoto, K. 1999. Purification and biological characterization of hostspecific SV-toxins from Stemphylium vesicarium causing brown spot of European pear. Phytopathology 89:947-953.

Culture filtrates of a pathogenic isolate (IT37) of Stemphylium vesicarium, causing brown spot of European pear, induced veinal necrosis only on pear leaves susceptible to the pathogen. Two host-specific toxins, SVtoxins I and II, were purified from culture filtrates of IT37 by successively using Amberlite XAD-2 resin adsorption, cellulose thin-layer chromatography, and high-performance liquid chromatography under three different sets of conditions. Susceptible cultivars showed veinal necrosis at a SV-toxin I concentration of 0.01 to $0.1 \mu \mathrm{g} / \mathrm{ml}$, whereas resistant
\end{abstract}

ABSTRACT cultivars were insensitive to the toxin at $1,000 \mu \mathrm{g} / \mathrm{ml}$. SV-toxins I and II caused a dose-dependent increase in electrolyte loss from susceptible leaf tissues. No increase in electrolyte loss was detected in leaf tissues from resistant cultivars. The results of physiological studies indicated that SVtoxins appear to have an early effect on plasma membranes of susceptible leaves. Spores of a nonpathogenic isolate induced necrotic lesions on susceptible leaves in the presence of a small amount of toxin. SV-toxins were detected in intercellular fluids obtained from diseased leaves after inoculation with the pathogen. The results indicate that SV-toxins I and II produced by $S$. vesicarium can be characterized as host-specific toxins.

Additional keyword: host-selective toxin.
Stemphylium vesicarium (Wallr.) E. Simmons causes brown spot of European pear (Pyrus communis L.), a disease of economic importance in the Mediterranean pear-production regions of Europe (22). Infection and necrosis occur on leaves, fruits, and twigs, with the maximum level of disease incidence occurring just prior to harvest. Chemical control of brown spot requires at least 15 to 25 fungicide sprays from fruit set to preharvest (21). Physiological (leaf age and fruit development stage) and environmental (temperature, relative humidity, and wetness duration) factors affect disease severity. Montesinos et al. (21) reported variation in the susceptibility of different European pear cultivars. Most of the highly susceptible cultivars are of great commercial interest in Europe (3).

Despite the importance of brown spot, little information on the mode of pathogenesis is available. The genus Stemphylium is related to the genus Alternaria; both belong to the order Moniliales (4). To date, there are at least 10 known host (including pear) and Alternaria disease combinations. Host-specific toxins (HSTs) are involved in disease development and are indispensable agents of virulence and pathogenicity for the pathogen $(23,24)$. In preliminary observations, $S$. vesicarium from European pear produced a HST (7), and the current study was undertaken to determine whether the toxin is the primary pathogenicity factor involved in brown spot of European pear. We found that two HSTs (SV-toxins I and II) were produced by $S$. vesicarium and established a procedure for purifying SV-toxins from culture filtrates of the pathogen. In

Corresponding author: K. Kohmoto; E-mail address: kohmoto@agr.tottori-u.ac.jp

Publication no. P-1999-0825-01R

(C) 1999 The American Phytopathological Society addition, biological activities and physiological effects of the toxins on host plants were investigated. Some preliminary results have been published (26-28).

\section{MATERIALS AND METHODS}

Fungal isolates. Eight isolates (IT34, IT35, IT36, IT37, IT38, IT40, IT41, and IT42) of $S$. vesicarium from European pear grown in Italy were used. An isolate (IT39) from asparagus also was used. All isolates were purified by single-spore isolation and stored in $20 \%$ glycerol at $-80^{\circ} \mathrm{C}$ until use.

Plants. European pear (cvs. Alexandrine Douillard, Bartlett, Conference, General Leclerc, La France, Le Lectier, and Passe Crassane), Japanese pear (cvs. Chojuro, Nijisseiki, and Osa Nijisseiki), and other nonhost plants, such as apple (cv. Mahe 7), onion, rose, and tomato (cv. Earlypak 7), were used. All plants were grown in pots in a glasshouse under controlled conditions.

Culture and sporulation. Fungal cultures were maintained on potato dextrose agar slants at $25^{\circ} \mathrm{C}$. For toxin production, small pieces from mycelial mats were placed in 500-ml flasks containing $200 \mathrm{ml}$ of potato dextrose broth (PDB) and incubated at $25^{\circ} \mathrm{C}$ on a rotary shaker $(120 \mathrm{rpm})$ under continuous diffused light for 10 days. Conidial spores were obtained as described previously for $S$. vesicarium (21).

Pathogenicity test. Pathogenicity of different isolates of $S$. vesicarium on various host and nonhost plants was determined by sprayinoculation with spores. Fresh young leaves were detached from plants and washed with water. Leaves were inoculated by spraying a spore solution $\left(5 \times 10^{5}\right.$ spores per $\left.\mathrm{ml}\right)$ with an atomizer and incubated in a moist chamber at $25^{\circ} \mathrm{C}$ for $24 \mathrm{~h}$. The number of lesions per square centimeter was determined. Each assay was repeated three times. 
Isolation of crude toxin from culture filtrates. $S$. vesicarium cultures grown for 10 days under continuous shaking were harvested by filtration through four layers of muslin cloth and two layers of Miracloth. The culture filtrate $(\mathrm{CF})$ was adjusted to $\mathrm{pH} 5.5$ with $10 \% \mathrm{NaH}_{2} \mathrm{PO}_{4}$ and was stirred with resin (Amberlite XAD-2, Organo Co. Ltd., Tokyo) for $4 \mathrm{~h}$ to adsorb toxins. Adsorbed resin was packed in a column, washed with water, and eluted with 5 volumes of methanol. The procedure was repeated three times to increase toxin recovery. The eluate was evaporated until dry under reduced pressure at $40^{\circ} \mathrm{C}$ with a rotary evaporator.

High-performance liquid chromatography. Analytical, semipreparative, and preparative high-performance liquid chromatographies (HPLC) were performed with two HPLC systems: one equipped with a L-3000 photodiode array detector, a L-5000 LC controller, a L-6000 pump, and a D-2500 chromatointegrator (Hitachi Scientific Instrument Co. Ltd., Tokyo), and one equipped with a SPD-10A UV-VIS detector, a RID-6A refractive index detector, a LC-6A liquid chromatograph, and a C-R4A chromatopac (Shimadzu Corp., Kyoto, Japan). Toxin samples in methanol were filtered with a $0.2-\mu \mathrm{m}$-pore filter (Millipore Corp., Bedford, MA) to remove insoluble materials and subjected to HPLC analysis on appropriate columns at room temperature (Fig. 1). Toxins were extracted with methanol from cellulose powder scraped from the toxic zone $\left(\mathrm{R}_{f}\right.$ value of 0.4 to 0.6 ) of thin-layer chromatography (TLC) plates.

Extraction, molecular sieving, heat, and proteinase treatments. The extractability of SV-toxins by different organic solvents (benzene, butanol, chloroform, diethyl ether, ethyl acetate, and petrole-

\section{Culture filtrate} - Adsorbed on Amberlite XAD-2 (pH 5.5) for $4 \mathrm{~h}$.
Eluted with pure methanol.

\section{Methanol eluate}

\section{HPLC, 1st}

solvent: (methanol/ deionized water/ acetic acid, 40:59:1, v/v), flow rate: $5.0 \mathrm{ml} / \mathrm{min}, 260 \mathrm{~nm}$, column: Develosil ODS-5 (20 X250 mm) (Nomura Chemical Co. Ltd., Tokyo).

Toxic fraction (Rt: 17-24 min)

\section{- Cellulose TLC} solvent: ( $n$-butanol/ acetic acid/ deionized water, $4: 1: 1, v / v)$, solid phase: cellulose (Funakoshi Co. Ltd., Tokyo).

Toxic fraction (Rf: 0.4-0.6)

\section{- HPLC, 2nd} solvent: (methanol/ deionized water/ acetic acid, 50:49:1, v/v), flow rate: $1.0 \mathrm{ml} / \mathrm{min}, 220 \mathrm{~nm}$, column: Partisil ODS-2 ( $8 \times 150 \mathrm{~mm})$ (Wako Pure Chemical Industries Ltd., Osaka).

Toxic fraction (Rt: $12-16 \mathrm{~min}$ )

$$
\begin{aligned}
& \text { HPLC, 3rd } \\
& \text { solvent: (methanol/ deionized water/ acetic acid, } \\
& \text { 50:49:1, v/v), flow rate: } 1.0 \mathrm{ml} / \mathrm{min}, 220 \mathrm{~nm}, \\
& \text { column: Cosmosil } 5 \mathrm{C}_{18} \text {-AR }(10 \times 250 \mathrm{~mm} \text { ) (Nacalai } \\
& \text { Tesque } / \mathrm{nc} ., \text { Tokyo). } \\
& \text { SV-toxin I (Rt: } 10 \mathrm{~min}) \text {, and } \\
& \text { SV-toxin II (Rt: } 12 \mathrm{~min})
\end{aligned}
$$

Fig. 1. Purification steps for isolating SV-toxins from culture filtrates of Stemphylium vesicarium (IT37). um ether) was tested. The approximate molecular weights of SVtoxins were estimated by passing CFs through different molecular sieves (Nihon Millipore Ltd., Yonezawa, Japan). The effect of heat on toxicity was observed by subjecting CFs to increasing temperatures of $40,60,80$, and $100^{\circ} \mathrm{C}$ and autoclaving for $30 \mathrm{~min}$. The effect of proteinases on toxicity was determined as described for a phytotoxin from Fusarium solani (12). Proteinase K $(50 \mu \mathrm{g} / \mathrm{ml}$, Sigma Chemical Co., St. Louis) was added to $20 \mathrm{ml}$ of CF and incubated in a water bath at $37^{\circ} \mathrm{C}$ for $2 \mathrm{~h}$. The reaction was terminated by adding $0.5 \mathrm{mM}$ phenylmethylsulfonyl fluoride (Sigma). CFs also were treated with pepsin (Sigma) at $10 \mathrm{mg} / \mathrm{ml}$ and incubated at $37^{\circ} \mathrm{C}$ for $2 \mathrm{~h}$. The toxicity in each case was evaluated by a leaf necrosis assay.

Leaf necrosis assay. The biological activity and host specificity of toxins were determined by a leaf necrosis assay on susceptible and resistant pear leaves (15). Fresh young leaves were detached from plants and washed with water. After removing midribs, the lower surface of a leaf was scratched near the center with a sharp needle. Sample solution $(20 \mu \mathrm{l})$ was applied to each wound site. Several dilutions were tested. Leaves were incubated in a moist chamber at $25^{\circ} \mathrm{C}$ for $24 \mathrm{~h}$, and necrosis around the wound site was recorded. Lesion area was recorded by tracing the necrotic area from the leaf to graph paper. Leaves of the same age were used for each experiment. Each assay was repeated three times.

Infection induction assay. To observe the effect of SV-toxins on the infection behavior of a nonpathogenic isolate of $S$. vesicarium (IT42), an infection induction assay was conducted as described by Kohmoto (15). IT42 spores were collected from petri dishes and thoroughly washed in deionized water with three cycles of centrifugation $(500 \times g$ for $3 \mathrm{~min})$. Washed spores were resuspended in a diluted toxin solution $(0.1 \mu \mathrm{g} / \mathrm{ml})$ or deionized water as a control. Spores were adjusted to $5 \times 10^{5} / \mathrm{ml}$, using Thoma's hemacytometer, and sprayed onto the lower surface of freshly detached leaves of susceptible pear. Leaves were placed on urethane foam mats in a moist chamber and incubated for $24 \mathrm{~h}$ at $25^{\circ} \mathrm{C}$. Small necrotic lesions were recorded as a sign of successful invasion by nonpathogenic spores.

Analysis of SV-toxins in spore-germination fluids. Analysis of toxins in spore-germination fluids (SGFs) was done as described by Kohmoto et al. (16). Spore suspensions $\left(50 \mathrm{ml}\right.$ at $5 \times 10^{5}$ spores per $\mathrm{ml}$ ) of a highly sporulating isolate, IT36, were poured onto sterile paper towels in plastic chambers $(33 \times 23 \times 6 \mathrm{~cm})$. Spores were incubated at $25^{\circ} \mathrm{C}$ and observed by light microscopy until an 80 to $90 \%$ germination rate was obtained. The paper towels were squeezed to recover germination fluids, deionized water $(20 \mathrm{ml}$ per chamber) was added, and the towels were squeezed again. Collected germination fluids were filtered through Toyo No. 2 filter paper (Toyo Roshi, Tokyo) to remove spores, evaporated until dry, and dissolved in methanol. The presence of toxicity in SGFs was analyzed by leaf necrosis assay as described above.

Collection of intercellular fluids from diseased leaves. Detached leaves from susceptible and resistant pear were inoculated with spore suspensions $\left(5 \times 10^{5} / \mathrm{ml}\right)$ by spraying with an atomizer and were incubated for $24 \mathrm{~h}$ in a moist chamber at $25^{\circ} \mathrm{C}$. Leaves showing small necrotic lesions at an early stage were selected. Intercellular fluids (IFs) were isolated from leaf tissues by modifying the method of Hammond-Kosack (9). Incubated leaves were cut into 0.5 -cm-wide strips. Smaller leaves were left intact. Cut leaves were rinsed with water for $\approx 15 \mathrm{~min}$ to remove all cytoplasmic contamination from the cut edges. Washed leaves were vacuum-infiltrated with water for $15 \mathrm{~min}$ at room temperature and rolled into the barrel of a $20-\mathrm{ml}$ plastic syringe. Syringes were placed in centrifuge tubes and centrifuged at $800 \times g$ for $10 \mathrm{~min}$. IFs collected from the bottom of centrifuge tubes were filtered with a $0.2-\mu \mathrm{m}$-pore filter (Millipore) and tested for toxicity by leaf necrosis assay as described above.

Electrolyte leakage assay. Electrolyte loss from leaf tissues was determined according to Otani's procedure (15). Ten leaf disks, 
$1 \mathrm{~cm}$ in diameter, were cut from freshly harvested young pear leaves with a leaf puncher (Open Industries Co. Ltd., Tokyo). Disks were vacuum-infiltrated for 20 min with SV-toxin solution or deionized water as a control. After rinsing with deionized water, leaf tissues were placed in flasks containing $10 \mathrm{ml}$ of deionized water and incubated in a reciprocal shaker $\left(120\right.$ strokes per min) at $27^{\circ} \mathrm{C}$. Conductance of ambient solutions was measured at different time intervals with a conductivity meter (CM-4OS, TOA Electronics Ltd., Tokyo; $k=1.0)$.

\section{RESULTS}

Pathogenicity of $S$. vesicarium. Isolates of $S$. vesicarium showed different degrees of virulence on host and nonhost plants. IT34, IT35, IT36, IT37, and IT38 were pathogenic on European pear (cvs. Alexandrine Douillard, Conference, General Leclerc, La France, Le Lectier, and Passe Crassane), but IT39, IT40, IT41, and IT42 were nonpathogenic (Table 1). Interestingly, an asparagus isolate, IT39, and a nonpathogenic European pear isolate, IT41, were pathogenic on Japanese pear (cvs. Chojuro, Nijisseiki, and Osa Nijisseiki) but not on European pear. CFs of IT37 showed higher toxicity on
European pear cultivars compared with the other isolates tested. Among the European pear cultivars, Alexandrine Douillard (in Japan, the cultivar is grown locally under the name Yoshimoto) showed higher sensitivity to CFs of IT37 (Table 2). The host range sensitive to the toxicity of CFs was comparable to the susceptibility of cultivars to the pathogen (Tables 1 and 2).

Purification of SV-toxins from culture filtrates of $S$. vesicarium. SV-toxins I and II were purified from CFs of $S$. vesicarium as described above. The purification procedure for SV-toxins is summarized in Figure 1. Non-host-specific toxins also were produced by $S$. vesicarium (Fig. 2), causing necrotic lesions on host (pear) and nonhost plants, such as apple, onion, rose, and tomato. Production of SV-toxins was highest after 10 days of incubation in PDB compared with other media (Czapek's-Dox, Fries, Richards, and V8 juice). The toxicity of CFs began decreasing 12 days after incubation. SV-toxins remained in the water phase during extraction with different organic solvents (benzene, butanol, chloroform, diethyl ether, ethyl acetate, and petroleum ether). SV-toxins in CFs were passed through molecular sieves with 5,000, 10,000 and 30,000 molecular weight cutoffs. Toxicity in CFs was stable when subjected to different high temperatures and proteinase treatments.

TABLE 1. Pathogenicity ${ }^{\mathrm{a}}$ of Stemphylium vesicarium isolates on host and nonhost plants

\begin{tabular}{|c|c|c|c|c|c|c|c|c|c|}
\hline \multirow[b]{2}{*}{ Plant } & \multicolumn{9}{|c|}{ Isolate $^{\mathrm{b}}$} \\
\hline & IT34 & IT35 & IT36 & IT37 & IT38 & IT39 & IT40 & IT41 & IT42 \\
\hline \multicolumn{10}{|l|}{ European pear cultivar } \\
\hline Alexandrine Douillard & $22 \pm 4$ & $8 \pm 2$ & $32 \pm 4$ & $36 \pm 3$ & $26 \pm 2$ & 0 & 0 & 0 & 0 \\
\hline Conference & $21 \pm 4$ & $12 \pm 3$ & $27 \pm 3$ & $29 \pm 4$ & $28 \pm 4$ & 0 & 0 & 0 & 0 \\
\hline General Leclerc & $2 \pm 1$ & $8 \pm 3$ & $10 \pm 4$ & $8 \pm 2$ & $29 \pm 3$ & 0 & 0 & 0 & 0 \\
\hline La France & $34 \pm 3$ & $5 \pm 2$ & $12 \pm 3$ & $27 \pm 4$ & $14 \pm 2$ & 0 & 0 & 0 & 0 \\
\hline Le Lectier & $7 \pm 2$ & $8 \pm 2$ & $14 \pm 3$ & $18 \pm 2$ & $16 \pm 4$ & 0 & 0 & 0 & 0 \\
\hline \multicolumn{10}{|l|}{ Japanese pear cultivar } \\
\hline Chojuro & 0 & 0 & 0 & 0 & 0 & $37 \pm 4$ & 0 & $6 \pm 3$ & 0 \\
\hline Nijisseiki & 0 & 0 & 0 & 0 & 0 & $36 \pm 2$ & 0 & $5 \pm 2$ & 0 \\
\hline Osa Nijisseiki & 0 & 0 & 0 & 0 & 0 & $29 \pm 3$ & 0 & $8 \pm 2$ & 0 \\
\hline \multicolumn{10}{|l|}{ Apple cultivar } \\
\hline Mahe 7 & 0 & 0 & 0 & 0 & 0 & 0 & 0 & 0 & 0 \\
\hline
\end{tabular}

${ }^{a}$ Expressed as number of lesions per square centimeter of leaf inoculated with $5 \times 10^{5}$ spores per ml. Observations were made after $24 \mathrm{~h}$ of incubation at $25^{\circ} \mathrm{C}$.

b Values are the means plus/minus standard deviation of three experiments.

TABLE 2. Host-specific toxicity of Stemphylium vesicarium (IT37) culture filtrate on host and nonhost plants

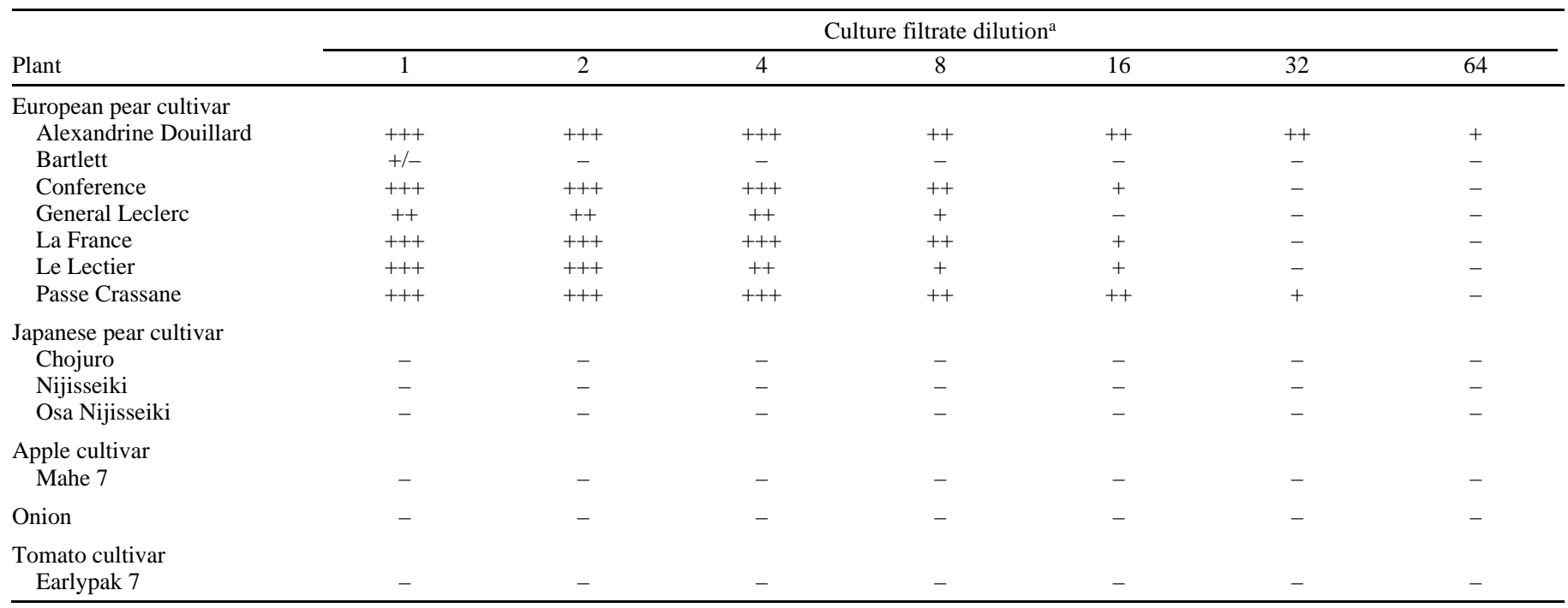

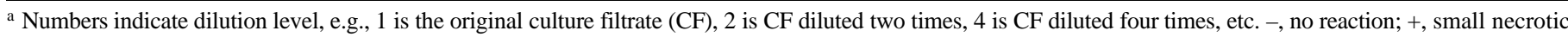
spot around the wound; ++ , necrosis expanded from wound sites; +++ , necrosis covered the entire area. 
Toxicity was always detected at the base line during the development of samples under different solvent systems, such as chloroform/methanol (85:15, vol/vol), chloroform/methanol/acetic acid (85:15:1, vol/vol/vol), ethanol/ethyl acetate/deionized water (80:20:5, $\mathrm{vol} / \mathrm{vol} / \mathrm{vol})$, ethyl acetate/methanol (3:1, vol/vol), and hexane/methanol/deionized water $(6: 2: 2, \mathrm{vol} / \mathrm{vol} / \mathrm{vol})$, on cellulose TLC plates.

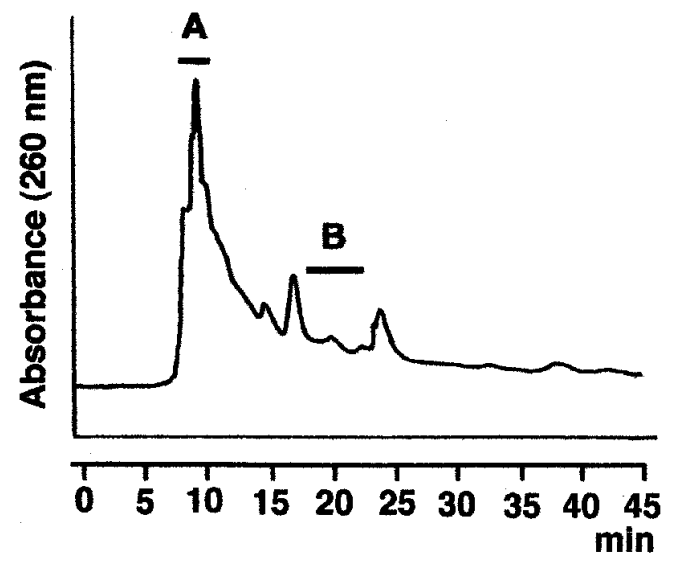

Fig. 2. High-performance liquid chromatography profile of crude toxin preparations. Solvent: methanol/deionized water/acetic acid, 40:59:1, vol/vol/vol; flow rate: $5.0 \mathrm{ml} / \mathrm{min}$; column: Develosil ODS-5 $(20 \times 250 \mathrm{~mm})$. A: Retention time of 8 to $12 \mathrm{~min}$ (non-host-specific toxins); B: retention time of 17 to $24 \mathrm{~min}$ (host-specific SV-toxins I and II).
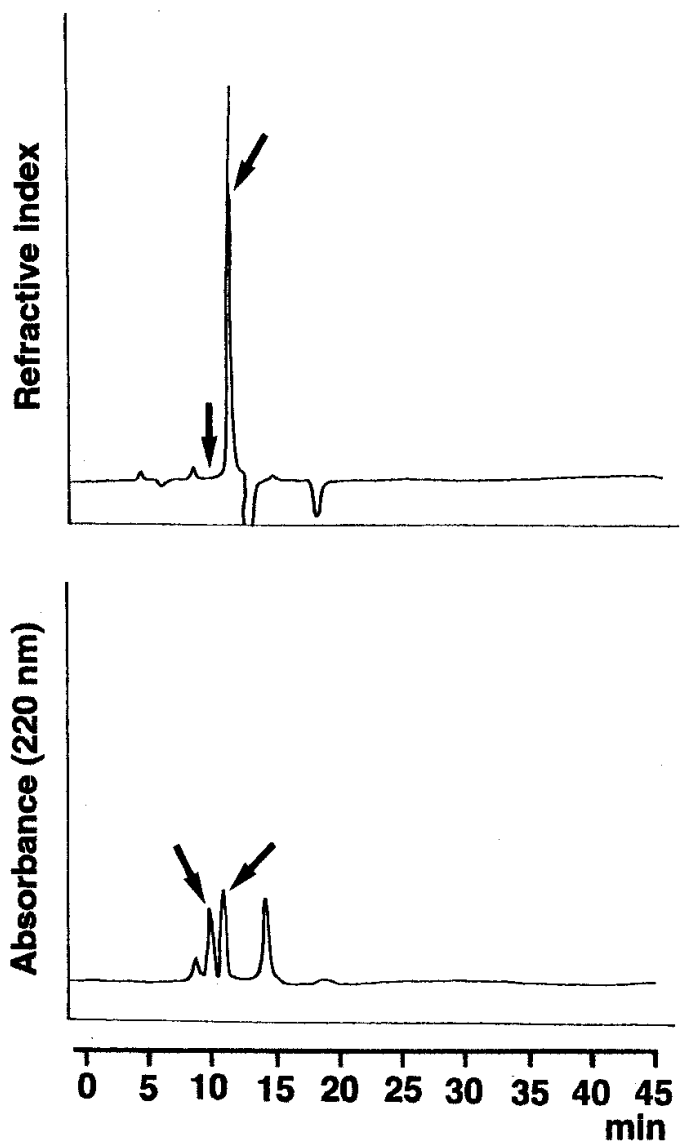

Fig. 3. High-performance liquid chromatography profiles of SV-toxins with a RI (reflectance index) detector (top), and UV-VIS detector $(220 \mathrm{~nm}$ ) (bottom). Solvent: methanol/deionized water/acetic acid, 50:49:1, vol/vol/vol; flow rate: $1.0 \mathrm{ml} / \mathrm{min}$; column: Cosmosil $5 \mathrm{C}_{18}$ - $\mathrm{AR}(10 \times 250 \mathrm{~mm})$. Arrows indicate toxin peaks. The left arrows (retention time of $10 \mathrm{~min}$ ) indicate the first toxin (SV-toxin I), which was not detected by the RI detector. The right arrows (retention time of $12 \mathrm{~min}$ ) indicate the second toxin (SV-toxin II), which was detected by both the RI and UV-VIS detectors.
Toxicity was located at $\mathrm{R}_{f}$ values of 0 to 0.4 with chloroform/methanol/acetic acid (60:35:1, vol/vol/vol) and 0.1 to 0.3 with ethyl acetate/acetic acid/deionized water (6:3:1, vol/vol/vol). The best resolution of toxins on cellulose TLC plates among different solvents was obtained at a $\mathrm{R}_{f}$ value of 0.4 to 0.6 with $n$-butanol/acetic acid/ deionized water $(4: 1: 1, \mathrm{vol} / \mathrm{vol} / \mathrm{vol})$. After the final HPLC with a Cosmosil $5 \mathrm{C}_{18}$-AR column $(10 \times 250 \mathrm{~mm}$; Nacalei Tesque Inc., Tokyo), the retention time for SV-toxins I and II was 10 and $12 \mathrm{~min}$, respectively. SV-toxins were detected with weak UV absorption at $220 \mathrm{~nm}$ by a UV-VIS detector, and SV-toxin II was also detected by a reflectance index (RI) detector (Fig. 3). Ninhydrin reagent produced pink spots in response to SV-toxins I and II.

Biological characterization of SV-toxins. The typical vein necrosis caused by SV-toxin I on susceptible leaves is shown in Figure 4. SV-toxin I at a concentration of 0.01 to $0.1 \mu \mathrm{g} / \mathrm{ml}$ induced veinal necrosis on leaves of susceptible cultivars but not on resistant cultivars even at a $10^{4}$-fold increase in concentration (Table 3 ). Visible necrosis on leaves of susceptible pear appeared at $24 \mathrm{~h}$ after incubation when treated with SV-toxin I at $0.1 \mu \mathrm{g} / \mathrm{ml}$. SV-toxin II was 10-times less toxic compared with SV-toxin I (Fig. 5). Younger leaves were more sensitive to toxins compared with older leaves. European pear cv. Alexandrine Douillard was highly susceptible

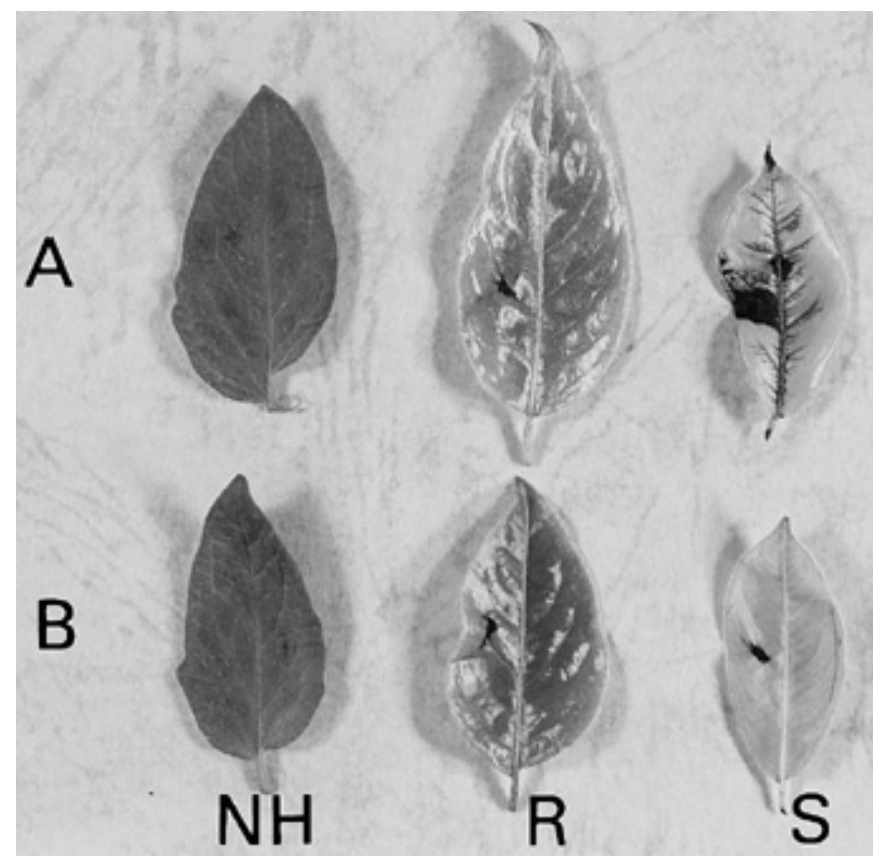

Fig. 4. Host-specific toxicity of SV-toxin I. NH, nonhost (tomato cv. Earlypak 7); R, resistant (Japanese pear cv. Chojuro); S, susceptible (European pear cv. La France). Leaves were treated with A, SV-toxin I at $50 \mu \mathrm{g} / \mathrm{ml}$; and $\mathbf{B}$, deionized water (control).

TABLE 3. Host-specific toxicity of SV toxin I from Stemphylium vesicarium

\begin{tabular}{lc}
\hline Plant & Dilution end point of necrotic toxicity \\
\hline European pear cultivar & \\
$\quad$ Alexandrine Douillard & 0.01 \\
Bartlett & 100 \\
Conference & 0.1 \\
General Leclerc & 0.1 \\
La France & 0.1 \\
Le Lectier & 0.1 \\
Passe Crassane & 0.1 \\
Japanese pear cultivar & \\
Chojuro & $>1,000$ \\
Nijisseiki & $>1,000$ \\
Osa Nijisseiki & $>1,000$ \\
\hline
\end{tabular}

${ }^{a}$ Minimum concentration (micrograms per milliliter) at which necrosis occurred due to treatment with SV toxin I. 
to the pathogen and sensitive to SV-toxin I (Table 3 and Fig. 5). Purified toxins showed high host-specific toxicity only to European pear cultivars, which were also highly susceptible to the pathogen (Table 3). Bartlett, a moderately resistant European pear cultivar, showed veinal necrosis induced by SV-toxin I at a concentration of $100 \mu \mathrm{g} / \mathrm{ml}$ (Table 3). Japanese pear cultivars, nonhost plants of the brown spot pathogen, were resistant to SV-toxin I at $1,000 \mu \mathrm{g} / \mathrm{ml}$. Therefore, a positive correlation was obtained between toxin production and pathogenicity of different pathogenic and nonpathogenic isolates.

The effect of SV-toxin I on the infection behavior of a nonpathogenic isolate of $S$. vesicarium (IT42) also was studied (Table 4). When avirulent spores of IT42 were inoculated in the presence of the toxin $(0.1 \mu \mathrm{g} / \mathrm{ml})$, they produced necrotic lesions on leaves of susceptible European cultivars but not on resistant Japanese cv. Nijisseiki. Similarly, in the presence of SV-toxin II $(1.0 \mu \mathrm{g} / \mathrm{ml})$, spores of nonpathogenic isolates also induced production of necrotic lesions only on susceptible European pear cultivars (data not shown). No necrotic lesions appeared after inoculation with spores without added toxins nor when only the toxins were sprayed on leaves.

Detection of SV-toxins in SGFs and IFs. SV-toxins could not be detected in SGFs of the pathogen after repeated experiments. However, the toxins were detected in IFs collected from leaves of susceptible European cultivars that were inoculated with highly virulent isolate IT37. SV-toxins were absent in corresponding IFs from the resistant Japanese pear cultivar, as well as in IFs from control treatments (Table 5).

Effect of SV-toxins on electrolyte loss from leaf tissues. SVtoxins caused a significant increase in electrolyte loss from susceptible leaves (Fig. 6). A detectable increase in electrolyte loss occurred at $1 \mathrm{~h}$ after treatment with SV-toxin I and 8 to $12 \mathrm{~h}$ after treatment with SV-toxin II only on the susceptible cultivar (Fig. 6A). The results were comparable to toxicity, because SV-toxin II was 10-times less toxic compared with SV-toxin I. The electrolyte loss from susceptible cv. La France treated with deionized water was more than the electrolyte loss from resistant cv. Chojuro. However, there was no difference in electrolyte leakage from resistant cv. Chojuro among toxin and deionized water treatments. An increase in electrolyte loss was observed with increasing toxin concentrations only

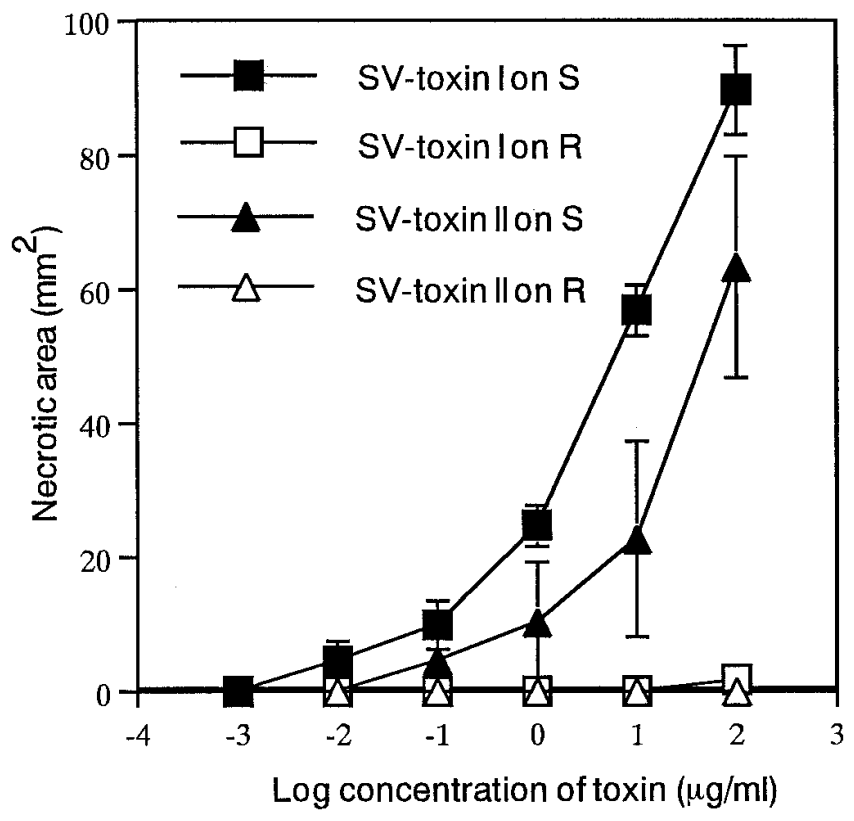

Fig. 5. Relationship between log concentration of SV-toxin and formation of veinal necrosis on susceptible and resistant leaf tissues. S, susceptible (European pear cv. Alexandrine Douillard); R, resistant (Japanese pear cv. Chojuro). Vertical bars indicate standard deviation of three sets of experiments. in susceptible cv. La France (Fig. 6B). The effects of SV-toxins on electrolyte loss on other susceptible cvs. (Alexandrine Douillard, Passe Crassane and Conference) were similar (data not shown).

\section{DISCUSSION}

The genus Stemphylium causes disease on a number of host plants, including cotton (18), garlic (5), lentil (2), oil seed rape (29), and tomato $(14,20,25)$. The species $S$. vesicarium has a wide host range, including asparagus (19), garlic (5), mango (13), lucerne (10), onion (11), and European pear $(8,21)$. S. vesicarium isolates from pear showed a high degree of host specificity. In inoculation tests, the isolates were pathogenic on European pear but could not cause disease on plants such as Japanese pear, tomato, and onion, suggesting there are pathotypes in $S$. vesicarium. The susceptibility of Japanese pear cultivars to an asparagus isolate of $S$. vesicarium (IT39) and a nonpathogenic European pear isolate (IT41) is an interesting area of research. A preliminary study performed in our laboratory showed that IT39 produced a toxin in culture, other than SV-toxin I or II, that caused selective toxicity on Japanese pear but not on European pear (K. Kohmoto, unpublished data). Therefore, Japanese pear may be a potential host of $S$. vesicarium. The comparison of chemical and biological characteristics of toxins, in combination with a host study, would allow the molecular basis of host differentiation among isolates of $S$. vesicarium to be elucidated.

A number of toxic metabolites from Stemphylium species have been studied (1), but none of them have been reported as containing HSTs. Recently, Cavanni et al. (7) reported that European pear isolates of $S$. vesicarium cause HSTs in CFs. In our study, the CFs of $S$. vesicarium (IT37) showed host-specific toxicity on various European pear cultivars (Table 2). Characteristic lesions produced by treatment with $\mathrm{CF}$ of the pathogen indicated the possible involvement of HSTs in disease development. A European pear cultivar, Alexandrine Douillard (Yoshimoto), that has been cultivated

TABLE 4. Effect of SV-toxin I on infection of susceptible and resistant pear leaves by spores of nonpathogenic Stemphylium vesicarium (IT42)

\begin{tabular}{lccc}
\hline & \multicolumn{3}{c}{ No. of necrotic lesions/cm ${ }^{2 \mathrm{a}}$} \\
\cline { 2 - 4 } Plant & $\mathrm{IT} 42+$ water & IT42 + toxin & Toxin \\
\hline European pear cultivar & 0 & $5 \pm 2$ & 0 \\
$\quad$ Alexandrine Douillard & 0 & $3 \pm 1$ & 0 \\
$\quad$ Conference & 0 & $4 \pm 2$ & 0 \\
$\quad$ La France & & 0 & 0 \\
Japanese pear cultivar & 0 & \\
$\quad$ Nijisseiki & &
\end{tabular}

TABLE 5. Detection of SV-toxins from Stemphylium vesicarium in intercellular fluids (IFs) of diseased pear leaves

\begin{tabular}{llcc}
\hline Treatment $^{\mathrm{a}}$ & Pear cultivar & $\begin{array}{c}\mathrm{IFs}^{\mathrm{b}} \\
(\mu \mathrm{l} / \mathrm{g} \text { of leaf })\end{array}$ & Toxicity $^{\mathrm{c}}$ \\
\hline S. vesicarium (IT37) & La France & 250 & + \\
& Chojuro & 210 & - \\
Deionized water & La France & 260 & - \\
& Chojuro & 200 & - \\
Control & La France & 200 & - \\
& Chojuro & 150 & - \\
\hline
\end{tabular}

a Freshly detached leaves were spray-inoculated either with a spore suspension of IT37 $\left(5 \times 10^{5}\right.$ spores per $\left.\mathrm{ml}\right)$ or with deionized water (control) and incubated for $24 \mathrm{~h}$ in a moist chamber at $25^{\circ} \mathrm{C}$. Leaves not treated served as a final control.

b IFs from leaves were obtained as described in text.

c + , present; -, absent. 
for years in Japan showed the highest sensitivity among the European pear cultivars tested. In addition, other susceptible European pear cultivars, such as Conference, La France, and Le Lectier, also are cultivated in Japan, and as such, the pathogen is now under quarantine to prevent any accidental introductions into Japan in the future. Another European pear cultivar, Bartlett, has shown variable responses to pathogen and CFs at different times (Tables 1 and 2).

Two HSTs, SV-toxins I and II, were purified from CFs of a highly virulent isolate of $S$. vesicarium (Fig. 3). SV-toxins I and II caused veinal necrosis at concentrations of 0.01 and $0.1 \mu \mathrm{g} / \mathrm{ml}$, respectively, on leaves of susceptible European pear (cv. Alexandrine Douillard), whereas resistant Japanese pear (cv. Chojuro) was insensi-
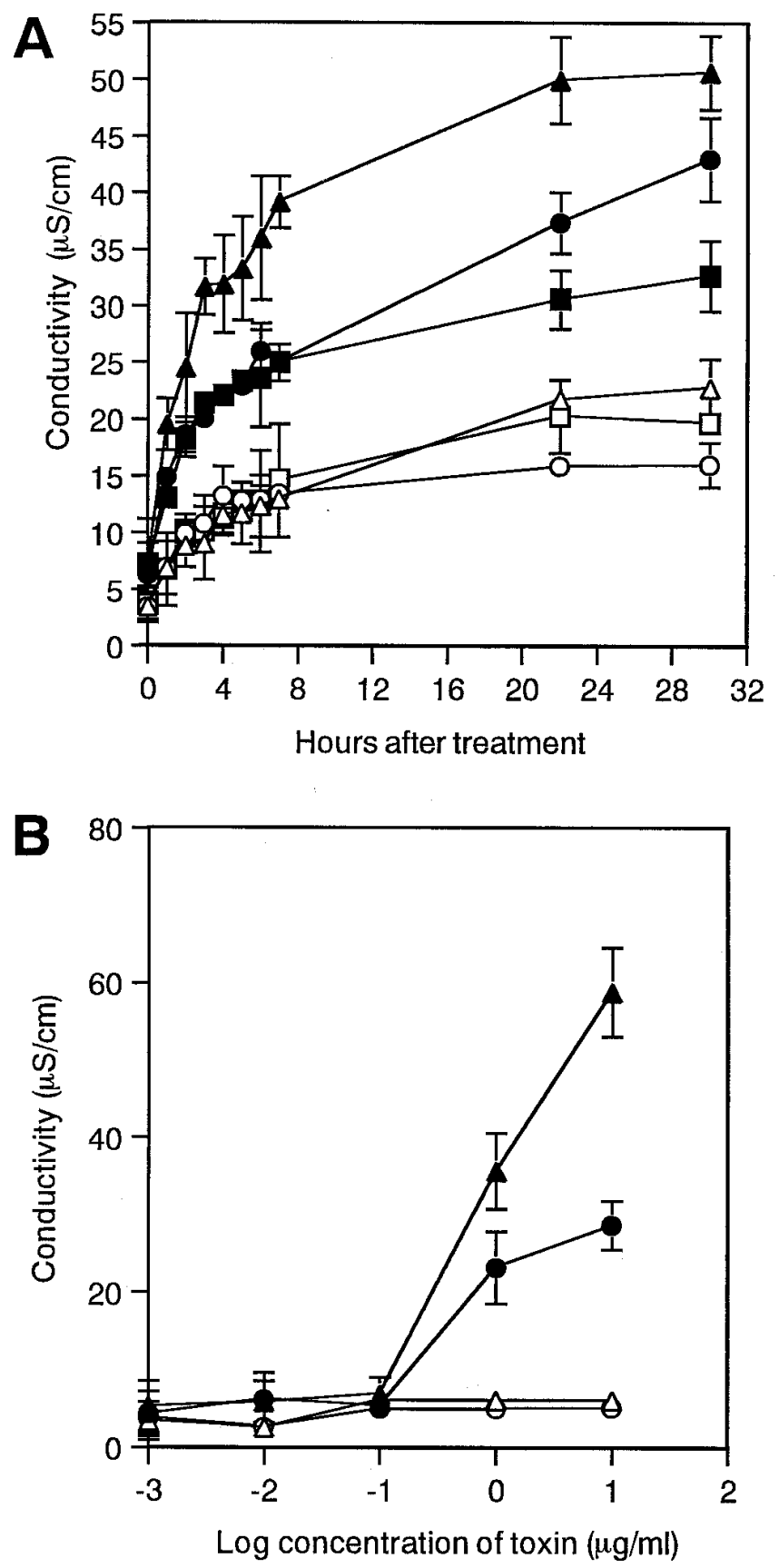

Fig. 6. A, Electrolyte loss from leaf disks at different time intervals after treatment with toxin $(1.0 \mu \mathrm{g} / \mathrm{ml})$ or water (control). B, Relationship between log concentration of toxin and electrolyte leakage recorded $12 \mathrm{~h}$ after treatment with toxin. $\boldsymbol{\Delta}$, Susceptible European pear cv. La France treated with SV-toxin I; -, SV-toxin II; $\mathbf{\square}$, deionized water; $\Delta$, resistant Japanese pear cv. Chojuro treated with SV-toxin I; O, SV-toxin II; and $\square$, deionized water. Vertical bars indicate standard deviation of three sets of experiments. tive to pure toxin at a $10^{4}$-fold increase in concentration (Fig. 5). Because SV-toxins I and II were isolated by the same purification steps (Fig. 1) and only the final step resolved them as individual peaks (Fig. 3), the toxins appear to have similar chemical natures. $\mathrm{SV}$-toxins appear to be low molecular weight compounds (MW < $5,000)$, heat stable, and nonproteinaceous. They also are highly hydrophilic compounds, because they are always recovered from the water phase during chemical extraction. The chromatographic behavior of these toxins under different solvent systems on cellulose TLC plates also suggests a hydrophilic nature. The highly hydrophilic nature and low molecular weights of SV-toxins were a major obstacle during purification. A strong ninhydrin-positive response for SV-toxins suggested the possible presence of amine group(s). Structural analysis of SV-toxins is currently in progress.

The pathogenicity of Stemphylium strains is positively correlated with the ability to produce SV-toxins. The sensitivity of pear cultivars to these toxins is directly correlated to their susceptibility to the causal pathogen (Table 3). The presence of SV-toxins at infection sites had a predisposing effect (17) on susceptible leaves invaded by nonpathogenic isolates of Stemphylium (Table 4). We could not confirm the release of SV-toxins during spore germination, which may be explained by the fact that less virulent isolates of the pathogen were used to detect toxins in SGFs, because highly virulent isolates (Table 1) were not efficient in sporulation under laboratory conditions. Secondly, the possibility of in planta toxin production during spore germination cannot be ruled out, because SGFs were obtained from spores of the pathogen in vitro. Toxin production in planta may be induced only by host factors, as was reported recently for AB-toxins produced by Alternaria brassicicola that cause black leaf spot of Brassica spp. (24). Stemphylium invades host tissues intercellularly (25), and SV-toxins were surveyed in the IFs of inoculated leaves. The presence of toxins in IFs was confirmed only in susceptible European cultivars; toxins were absent from IFs of resistant Japanese pear cultivars inoculated by $S$. vesicarium (IT37) and in control treatments. Because IFs were collected from leaves showing premature necrotic lesions $24 \mathrm{~h}$ after inoculation, toxins seemed to be involved in the early infection process. The infection-inducing activity and in situ presence of toxins during early necrosis formation suggest that SV-toxins play a key role in establishing the initial colonization of susceptible cultivars. The analysis of IFs obtained from inoculated susceptible and resistant leaves should provide an effective method of searching for molecules involved in signaling during pathogenesis. Therefore, SV-toxins fulfill the criteria determined for a toxic metabolite to be designated as host specific (15). This is the first report of an HST from Stemphylium pathogens.

SV-toxin treatments resulted in an increase in electrolyte loss from susceptible leaf tissues (Fig. 6), and SV-toxin I (1.0 $\mu \mathrm{g} / \mathrm{ml})$ induced significant electrolyte loss as early as $1 \mathrm{~h}$ after treatment. However, the effects of the toxins on electrolyte leakage were mild when compared with other HSTs, such as AK-, ACT-, and AF-toxins, whose primary target organelle is the plasma membrane (23). Unlike the exponential or linear increase in electrolyte loss with time for AK- and ACT-toxins, indicating a direct effect on plasma membranes, SV-toxins showed a parabolic increase in electrolyte loss with time, suggesting a direct or indirect effect on plasma membranes. In an independent study, Bugiani et al. (6) reported that a partially purified SV-toxin obtained from CFs of $S$. vesicarium induced an increase in oxygen uptake and in the activity of plasma membrane NADH/ferricyanide reductase in susceptible pear leaf tissues. Recent ultrastructural studies on the action site of SV-toxins indicated that plasmalemmal modifications in susceptible cells specifically occurred at plasmodesmata as early as $3 \mathrm{~h}$ after toxin treatment (P. Singh, unpublished data). Thus, plasma membrane disorders, caused directly or indirectly by SV-toxins appear to be the key or central event responsible for early pathogenesis on pear; the primary action site of SV-toxins remains an open question. 


\section{ACKNOWLEDGMENTS}

This work was supported by research grants 08044207 and 10556007 from the Ministry of Education, Science, Sports, and Culture of Japan. We thank R. Johnson for a critical reading of the manuscript and helpful discussion.

\section{LITERATURE CITED}

1. Andersen, B., Solerizzo, M., and Visconti, A. 1995. Metabolite profiles of common Stemphylium species. Mycol. Res. 99:672-676.

2. Bakr, M. A., and Ahmed, F. 1992. Development of Stemphylium blight of lentil and its chemical control. Bangladesh J. Plant Pathol. 8:39-40.

3. Berni, P., and Begalli, D. 1993. Situazione e prospettive economico commerciali delle pere. Pages 207-232 in: La Coltura del Pero per una Produzione Integrata. S. Fraccaroli, G. Bargioni, and A. Febi, eds. Camera di Commercio, Industria, Artigianato e Agricoltura di Verona, Italy.

4. Bessey, E. A. 1968. Fungi imperfecti: The imperfect fungi. Pages 572627 in: Morphology and Taxonomy of Fungi. Hafner Publishing Company, New York.

5. Boiteux, L. S., Lima, M. F., Menezes Sobrinho, J. A., and Lopes, C. A. 1994. A garlic (Allium sativum) leaf blight caused by Stemphylium vesicarium in Brazil. Plant Pathol. 43:412-414.

6. Bugiani, R., Negrini, N., Cocucci, M., and Cavanni, P. 1998. SV-toxin, partially purified from culture filtrates of Stemphylium vesicarium, induces an increase in oxygen uptake and in the activity of plasma membrane NADH:ferricyanide reductase in pear. Paper 1.2.18 in: Abstracts of the Proceedings of the 7th International Congress on Plant Pathology.

7. Cavanni, P., Bugiani, R., Zanotti, M., Ponti, I., Iori, R., Leoni, O., and Palmieri, S. 1993. Isolation and purification of a host-specific toxin elaborated by Stemphylium vesicarium agent of "brown spot" of European pear. Page 223 in: Abstracts of the Proceedings of the 6th International Congress on Plant Pathology.

8. Cavanni, P., and Ponti, I. 1994. Brown spot of pear: A mycopathogen always topical. Riv. Fruttic. Ortofloric. 56(12):37-42.

9. Hammond-Kosack, K. E. 1992. Preparation and analysis of intercellular fluid. Pages 15-21 in: Molecular Plant Pathology: A Practical Approach. Vol. 2. S. J. Gurr, M. J. McPherson, and D. J. Bowles, eds. Oxford University Press, New York.

10. Irwin, J. A. G., and Bray, R. A. 1991. Variation in virulence within the cool temperature biotype of Stemphylium vesicarium (Wallr.) Simmons, a lucerene leaf spot pathogen. Aust. J. Exp. Agric. 31:793-795.

11. Jakhar, S. S., Duhan, J. C., and Suhag, L. S. 1996. Studies on the epidemiology and survival of Stemphylium vesicarium (Wallr.) Simmons in debris and seeds of onion. Seed Res. 24:135-140.

12. Jin, H., Hartman, G. L., Nickell, C. D., and Widholm, J. M. 1996. Characterization and purification of a phytotoxin produced by Fusarium solani, the causal agent of soybean death syndrome. Phytopathology 86:277-282.

13. Johnson, G. I., Sangchote, S., and Cooke, A. W. 1990. Control of stem end rot (Dothiorella dominicana) and other postharvest diseases of mangoes (cv. Kensington Pride) during short- and long-term storage. Trop. Agric. 67:183-187.
14. Kamanna, B. C., and Ponnapa, K. M. 1995. Cultural characteristics and host range of Stemphylium lycopersici causing leaf spot of tomato. J. Mycopathol. Res. 33:11-14.

15. Kohmoto, K. 1992. Determination of host-selective toxins. Pages 51-73 in: Modern Methods of Plant Analysis New Series. Vol. 13, Plant Toxin Analysis. H. F. Linskens and J. F. Jackson, eds. Springer-Verlag, Berlin.

16. Kohmoto, K., Itoh, Y., Shimomura, N., Kondoh, Y., Otani, H., Kodama, M., Nishimura, S., and Nakatsuka, S. 1993. Isolation and biological activities of two host-specific toxins from the tangerine pathotype of Alternaria alternata. Phytopathology 83:495-502.

17. Kohmoto, K., Otani, H., Kodama, M., and Nishimura, S. 1989. Host recognition: Can accessibility to fungal invasion be induced by host-specific toxins without necessitating necrotic cell death? Pages 250-273 in: Phytotoxins and Plant Pathogenesis. A. Graniti, R. D. Durbin, and A. Ballio, eds. Springer-Verlag, Berlin.

18. Mehta, Y. R. 1998. Severe outbreak of Stemphylium leaf blight, a new disease of cotton in Brazil. Plant Dis. 82:333-336.

19. Menzies, S. A., Broadhurst, P. G., and Triggs, C. M. 1992. Stemphylium disease of asparagus (Asparagus officinalis L.) in New Zealand. N.Z. J. Crop Hortic. Sci. 20:427-433.

20. Min, J., Kim, B., Cho, K., and Yu, S. 1995. Grey leaf spot caused by Stemphylium lycopersici on tomato plants. Korean J. Plant Pathol. 11:282-284.

21. Montesinos, E., Moragrega, C., Llorente, I., and Vilardell, P. 1995. Susceptibility of selected European pear cultivars to infection by Stemphylium vesicarium and influence of leaf and fruit age. Plant Dis. 79:471-473.

22. Montesinos, E., Moragrega, C., Llorente, I., Vilardell, P., Bonaterra, A., Ponti, I., Bugiani, R., Cavanni, P., and Brunelli, A. 1995. Development and evaluation of an infection model for Stemphylium vesicarium on pear based on temperature and wetness duration. Phytopathology 85:586-592.

23. Otani, H., Kohmoto, K., and Kodama, M. 1995. Alternaria toxins and their effects on host plants. Can. J. Bot. 73 (suppl.1):S453-S458.

24. Otani, H., Kohnobe, A., Kodama, M., and Kohmoto, K. 1998. Production of a host-specific toxin by germinating spores of Alternaria brassicicola. Physiol. Mol. Plant Pathol. 52:285-295.

25. Shrestha, S. M., and Bhatnagar, M. K. 1988. Histopathological study of Stemphylium botryosum f. sp. lycopersici on tomato leaves. J. Inst. Agric. Anim. Sci. Nepal 9:51-55.

26. Singh, P., Bugiani, R., Cavanni, P., Kodama, M., Otani, H., and Kohmoto, K. 1997. Production of host-specific toxin by Stemphylium vesicarium causing brown spot of European pear. (Abstr.) Ann. Phytopathol. Soc. Jpn. 63:232.

27. Singh, P., Bugiani, R., Cavanni, P., Nakajima, H., Kodama, M., Otani, H., and Kohmoto, K. 1998. Purification, biological and chemical characterization of a host-specific SV-toxin from culture filtrates of Stemphylium vesicarium causing brown spot of European pears. Paper 1.8.23 in: $\mathrm{Ab}$ stracts of the Proceedings of the 7th International Congress on Plant Pathology.

28. Singh, P., Park, P., Bugiani, R., Cavanni, P., Nakajima, H., Kodama, M., Otani, H., and Kohmoto, K. 1998. Effects of SV-toxin(s) produced by Stemphylium vesicarium causing brown spot of European pear on plasma membranes of susceptible cultivars. (Abstr.) Ann. Phytopathol. Soc. Jpn. 64:618-619.

29. Solfrizzo, M., Strange, R. N., Sabia, C., and Visconti, A. 1994. Production of a toxin stemphol by Stemphylium species. Nat. Toxins 2:14-18. 